\title{
A METHOD OF EXTRACTING SHORELINE BASED ON SEMANTIC INFORMATION USING DUAL-LENGTH LiDAR DATA
}

\author{
YAO Chunjing ${ }^{\mathrm{a}, \mathrm{b}}$, WU Jiaman ${ }^{\mathrm{a},{ }^{*}}$, YUAN Zhaoxiang ${ }^{\mathrm{c}}$ \\ a. School of Remote Sensing Information and Information Engineering Wuhan University, \\ Hubei Wuhan, China-2014301630023@whu.edu.cn; \\ b. Key Laboratory for National Geographic Census (NGC), Hubei Wuhan, China- yaocj@whu.edu.cn; \\ c. State Power Economic Research Institute Beijing, China- zhangjiyong@ chinasperi.sgcc.com.cn;
}

KEY WORDS: Shoreline, Dual-wavelength LiDAR, Semantic Information, TIN progressive filtering, Eight-neighborhood filling, Pseudo grid

\begin{abstract}
:
Shoreline is a spatial varying separation between water and land. By utilizing dual-wavelength LiDAR point data together with semantic information that shoreline often appears beyond water surface profile and is observable on the beach, the paper generates the shoreline and the details are as follows: (1) Gain the water surface profile: first we obtain water surface by roughly selecting water points based on several features of water body, then apply least square fitting method to get the whole water trend surface. Then we get the ground surface connecting the under -water surface by both TIN progressive filtering method and surface interpolation method. After that, we have two fitting surfaces intersected to get water surface profile of the island. (2) Gain the sandy beach: we grid all points and select the water surface profile grids points as seeds, then extract sandy beach points based on eightneighborhood method and features, then we get all sandy beaches. (3) Get the island shoreline: first we get the sandy beach shoreline based on intensity information, then we get a threshold value to distinguish wet area and dry area, therefore we get the shoreline of several sandy beaches. In some extent, the shoreline has the same height values within a small area, by using all the sandy shoreline points to fit a plane $\mathrm{P}$, and the intersection line of the ground surface and the shoreline plane $\mathrm{P}$ can be regarded as the island shoreline. By comparing with the surveying shoreline, the results show that the proposed method can successfully extract shoreline.
\end{abstract}

\section{INTRODUCTION}

Shoreline is a spatial varying separation between water and land (E. H. Boak, 2005) . In order to protect the island from erosion, the intertidal area extraction plays an essential role in coastal protection design and sea level rise monitoring (D. Bellomo,1999). As the beaches along our study area do not possess clearly defined berms or scarps, and the vegetation line does not necessarily respond to oceanic changes, wet/dry line can be a substitute. The NPS has chosen wet/dry line, as the definition of shoreline for Assateague Island National Seashore (Harris M, 2005).

In the past, most of the researchers focused on modeling sea level rise (Leatherman S.P, 1983), mapping shoreline (Douglas B.C,1998), detecting shoreline changes (Douglas B.C., 1998) action is the key process for all the applications mentioned above. Several data sources such as: historical land-based surveys, coastal maps and charts, aerial images, beach surveys, multispectral/hyperspectral satellite images, LiDAR data and microwave sensors have been used to extract the shoreline locations. Land surveying is the most accurate method, but it is also the most labor intensive and costly relative to remote sensing and photogrammetry (Yang B.Y., 2012). Remote sensing data can delineate shorelines over large areas, but accuracy can sometimes be less than that of land surveying. That's why the shoreline on the satellite image is poorly estimated by distinguishing a line between dry and wet sandy beach. As the newer developed technology, the use of LiDAR to delineate shorelines is a relatively recent development (Pe'eri S., 2011.)

Different from previous study, semantic information was used in our research. As the humidity degree of different areas can be observed in intensity image, the wet/dry line can be distinguished. But directly extracting shoreline from LiDAR intensity data is still a difficult thing as there're other objects in other position have similar intensity values like the shoreline. Therefore semantic information of the shoreline was introduced. We used the semantic information that shoreline often appears beyond water surface profile and on the sandy beaches and gravel beaches as a foundation, and after obtaining water surface profile and getting beaches based on the water surface profile, we could extract whole island shoreline. For this method, though the shoreline could be found on both sandy beaches and gravel beaches in our study area, the feature of gravel beaches was hard to describe. Therefore we extracted all discrete sandy beach and gained sandy beach shorelines, then fit the shoreline points as a plane and had this plane and the ground surface intersected to get shoreline of the island. Another aspect distinguished this method from traditional method is the use of dual-wavelength LiDAR data, which helped us to get the water surface profile only by some of the water surface points as we could fit a tendency surface and have it intersected with the ground surface. The difference from previous study contributed to the efficiency and accuracy of this method.

The rest of this paper is organized as follows: In section 2, the data was introduced. In section 3, we described the method to obtain shoreline. In section 4, the experiment was demonstrated while section 5 gave a discussion of the research and section 6 for conclusion. 


\section{DATA}

\subsection{Data}

The LiDAR data were acquired from an average of $1000 \mathrm{~m}$ above ground level (AGL) in a period between March 2014 and March 15 of Wuzhi Island. The LiDAR system (Optech ALTM Aquarius) utilizes advanced technology in airborne positioning and orientation, enabling the collection of high-accuracy digital surface data, while recording four returns per laser pulses. The reported horizontal and vertical accuracies with the Optech system for the mission specifications of this project are 15-25 $\mathrm{cm}$ and $15 \mathrm{~cm}$, respectively. Green and IR frequencies are available in a single system. Meanwhile, different from the traditional LiDAR devices, its dual-wavelength LiDAR sensors can get the water surface data and the under-water ground surface data simultaneously, which enable its high performance in shallow or turbid water mapping and superior land/water discrimination and depth resolution

\subsection{Study Area}

Wuzhizhou Island was selected for this research to represent differing coastal environments and show a method to obtain the shoreline based on the various type of coast. Wuzhizhou Island is a famous tourism place in China with numerous species of precious plants and animals, which is located in the southernmost part of Hainan Island. The coast area is made of the soft white sand and hard rocks together with the man-made dock.

Gravel beach points in profile are distributed in a relatively random way, which suggested the gravel surface is not smooth. Therefore it's hard to describe the features by mathematical language. Here the wet/dry line was referred as shoreline. (Figure 1)

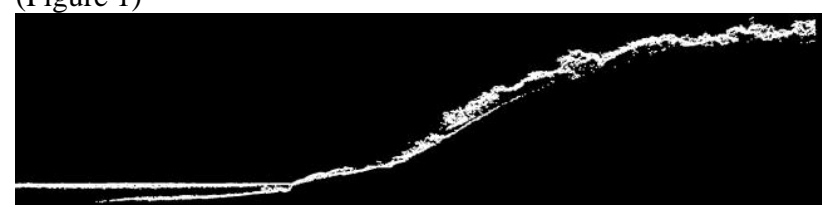

Figure.1 Profile for gravel coast.

Man-made duck points have a regular distribution and usually companied with a terrain risen up suddenly at the water surface profile. Therefore the water surface profile can also be considered as the shoreline because the seawater cannot pass over the duck and left moisture information on it. (Figure 2)

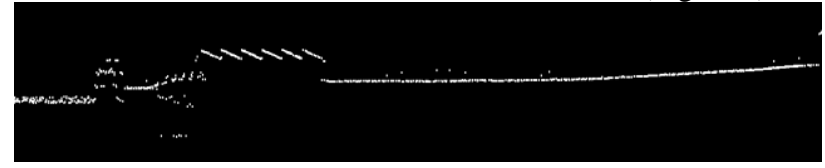

Figure.2 Profile for man-made coast.

Sandy beach points have a relatively smooth distribution with a sudden rise at the border of vegetation-covered area and sandy beach area, which can be considered as a feature to distinguish the sandy beach area. In this area, the water surface profile cannot be regarded as shoreline for the line varies under the tidal influence. Here the wet/dry line was referred as shoreline. (Figure 3)

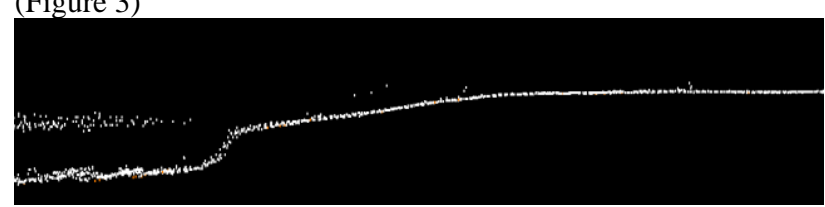

Figure.3 Profile for sandy beach.

\section{METHODOLOGY}

Semantic information actually refers to the use of surrounding environment of the shoreline. The shoreline will generally appears on reefs, beaches, etc. The use of homogeneous information of these area (smoothness of sandy beaches together with the dark reef, white beach in intensity image) could help to extract these area, therefore narrow the region for shoreline searching and avoid involving other objects which have the same intensity value with the wet/dry line. Based on this, we could obtain wet/dry line using intensity data in a relatively small area. As the features of gravel beach is hard to describe, we use sandy beach and man-made beach shoreline points to fit a plane. And the intersection line of the ground surface and the shoreline plane could be regarded as the island shoreline basing on the knowledge that shoreline in a small area has similar elevation.

By utilizing various information and characteristics of dualwavelength LiDAR point data together with semantic information and also features of targets such as smoothness of the sandy beach, the moisture of the sand and the intersection line of ground surface and the water surface, the paper generates the shoreline and the details are as below (Figure 4):

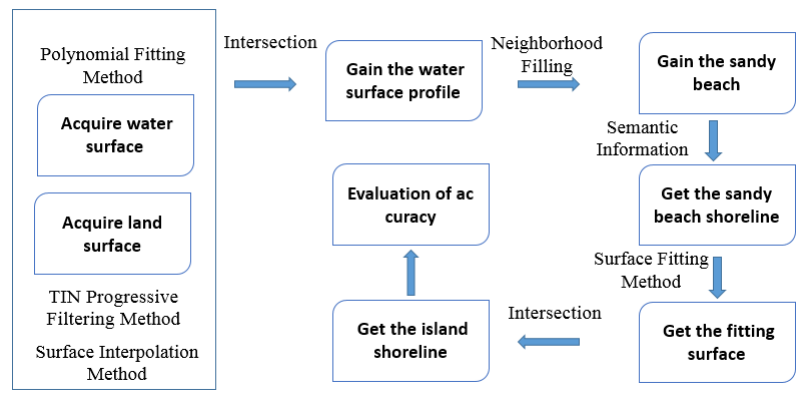

Figure 4: Flowchart of the proposed method

\subsection{Gain Water Surface}

The truth that point cloud data can be used for water extraction is based on several facts:

(1) Airborne LiDAR for terrestrial measurements operate at $1040-1060 \mathrm{~nm}$, which is located in the strong absorption zone of water (Brzank et al., 2008). With little laser echo, the water area is often given black in the post-processing laser data which is a significant feature that can be used;(2) In the LiDAR data, the closed water surface is usually a closed polygon with a ring (a small island in the water); (3) The water surface has relatively same elevation while the elevation of the water area boundary often has a step type (change Wang Z Y et al., 2010).

By utilizing features mentioned above, we extract water body in a variety of ways. In this paper, the dual-laser LiDAR data is used to extract the precisely shorelines by intersecting the ground and water surfaces.

The fitting surface should have two features: (1) The surface should be smooth as the elevation is almost the same; (2) The fitting surface should reflects the tendency of the original point cloud so it can be used in intersecting process. To satisfy two requirements, we applied least square fitting method to have the fitting surface.

Here we suppose the surface was a plane which could be described as: 


$$
a x+b y+z+c=0
$$

where $\quad x, y, z=$ the coordinates of the point.

$$
a, b, c=\text { the plane fitting parameter. }
$$

Therefore all points $\left(x_{i}, y_{i}\right)$ should satisfy the equation (2):

$$
x_{i} a+y_{i} b+c=-z_{i} \quad(i=1,2, \ldots, n)
$$

To describe the error $V$ in equation (2), the equation should be:

$$
V=x_{i} a+y_{i} b+c+z_{i}(i=1,2, \ldots, n)
$$

And can be represented in matrix form:

$$
V=A X-L
$$

where

$$
\mathbf{A}=\left(\begin{array}{ccc}
x_{i} & y_{i} & 1 \\
x_{2} & y_{2} & 1 \\
& \ldots & \\
x_{n} & y_{n} & 1
\end{array}\right) \quad \mathbf{L}=\left(\begin{array}{c}
-z_{1} \\
-z_{2} \\
\cdots \\
-z_{n}
\end{array}\right), \mathbf{X}=\left(\begin{array}{l}
a \\
b \\
c
\end{array}\right)
$$

Therefore the plane fitting parameter should be:

$$
X=(A T A)^{-1} A T L
$$

\subsection{Gain Under -Water Surface}

Underwater surface can also be considered as part of ground points. George Sithole concluded that the TIN progressive filtering method had a good performance on both large objects and small objects. Meanwhile, it extracted building on slopes very well, which helped to extract man-made dock and the terrain of sandy beach and gravel beach (Sithole. G,2003). By using TIN progressive filtering method (Axelsson. 2000), we obtain the ground points in which the under-water ground points included.

As showed in Figure 2, there are three kinds of coast in our study area. The first kind is gravel coast, whose point cloud appears to be random. The second kind is the Man- made coast, which constructed a relatively smooth surface while the sandy beach, also smooth, constructs a more steep surface. To obtain a TIN which well retained topographical features of these three kinds of coasts, we have procedures as follows:

Before the TIN progressive filtering, we should apply Delaunay algorithm to original point cloud to construct TIN and build index for every triangle vertex. Then the process should be like this:

(1)Select initial seeds. In this research, ground points which have lowest elevation was picked. (2)Determine the regional growth threshold. By picking seed point as the growth center to retain the feature of the man-made coast and gravel beach, we take several factors into consideration: max terrain angle, max iterative angle and max iterative distance.(3)Start Growing Process. The 8-neighborhood points are searched for the initial seed point, and the elevation value are obtained from the index of the neighborhood point. And then we determine whether the height difference between the neighborhood point and the seed point satisfy the threshold. If it satisfies, it is the ground point cloud. Otherwise, it is a non-ground point cloud. (4)End the Growing Process. We execute (3) until there was no other points satisfy the condition.
To lay a good foundation for later calculation, we should also fit discrete points to continuous surface. For the ground surface, it cannot be fitted by a simple function, so linear interpolation was utilized here, then the original point clouds could be described as a surface.

\subsection{Gain Water Surface Profile}

The intersecting line is hard to extract as original points are discrete. As we have already utilized the surface fitting method to transfer discrete point cloud to continuous surface. Based on the intersecting line of two surfaces, it's possible to obtain the water surface profile.

Here the intersection line between the surfaces is very critical, it is determined by the intersection of two surfaces, and thus determine the intersection of the direct method is to conduct the surface intersection, but the surface interpolation function is often complex, the cost of directly calculate it is relatively high. A more simple method is to utilize the topological relationship. First and foremost, we get several intersected points by intersecting the two surface lines in profiles (Figure 5 (c)) along one direction with equal intervals(Figure 5 (b)), then use curve interpolation function to achieve the construction of a smooth intersection line by connecting several intersected points, also regarded as water surface profile of the island (Figure 5 (a)) .
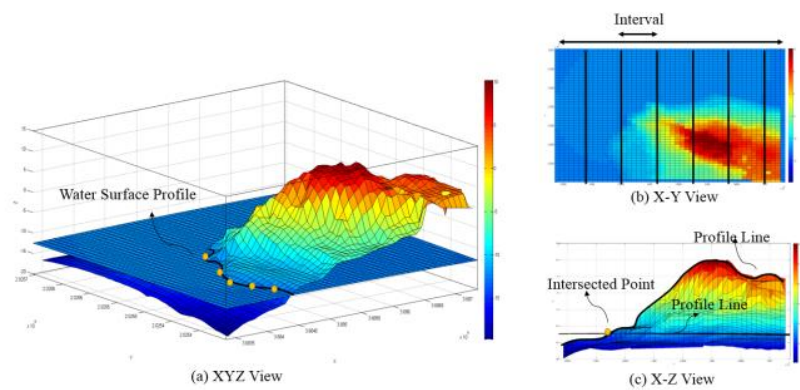

Figure 5: The water surface profile: (a) Water surface profile in 3D space (b) Choose interval in X-Y view; (c) Determine the intersected point of two profile.

\subsection{Gain Sandy Beach}

\subsubsection{Grid Data}

In order to extract sandy beach from large and high density point cloud data, point cloud preprocessing must be performed. Gong Liang (Gong Liang et al, 2012) have proposed a multi-scale virtual grid based on the LiDAR point cloud filtering method. This paper introduced the method for better data organization. The so-called "virtual grid" is based on the X, Y coordinates of the data grid, so that topological relationship between each point and its surrounding point has been implied in the array of the column of the grid (Shu Ning et al, 2005). The virtual grid data processing has three mainly advantages: First, this approach can effectively simplify the data, improve processing efficiency; the second is that makes it easy to use mature algorithm in photogrammetry and digital image processing; The third is it helps to overcome the error caused by data gap, therefore meets processing accuracy requirements. 
Describe the scope which the point clouds cover by a diagonal points set $(\min X, \min Y, \max X, \max Y)$. This Diagonal points set can determine a rectangle and dividing the rectangle to small rectangles whose size are $\left(D_{x}, D_{y}\right)$, could help us obtain the grid with $M$ rows and $N$ columns. The size of the grid is determined by data density and the average number of points within a single grid. The grid side length can be estimated as below:

$$
1=\sqrt{(\lambda * A) / n_{0}}
$$

Where $n_{0}=$ average number of points in a single grid.

$A=$ area of the small rectangle.

$\lambda=$ data coverage, which is an empirical parameter. The goal of this parameter is to prevent big data gaps from reducing data density, usually set as the area of a single small rectangle.

\subsubsection{Sandy Beach Features}

Elevation features: The elevation can be regarded as one of the sandy beach's features as the sandy beach always appears at the water surface profile and disappear at a certain distance from the profile, which is also the semantic information of sandy beach. Therefore, the water surface profile can be regarded as reference mark. From the grid where points are at the water surface profile, other points have a higher elevation are gradually added to the set which includes sandy beach point. To do this, the elevation difference between corresponding points should be taken in consideration. Using this method helped us narrow the searching scope.

Geometrical features: The research used features to obtain the whole sandy beach. Generally, the sandy beach surface is relatively smooth, which is quite different from natural gravel beaches. Therefore the direction of the TIN surface can be involved. To obtain the direction of TIN surface, we first constructed TIN for point cloud and set the three vertexes' coordinates which form the triangle (unit of TIN surface) are $\left(X_{1}, Y_{1}, Z_{1}\right),\left(X_{2}, Y_{2}, Z_{2}\right),\left(X_{3}, Y_{3}, Z_{3}\right)$, the area of the TIN unit is

$$
A=\frac{1}{2}\left\{\left|\begin{array}{ll}
Y_{1} & X_{1} \\
Y_{2} & X_{2}
\end{array}\right|+\left|\begin{array}{cc}
Y_{2} & X_{2} \\
Y_{3} & X_{3}
\end{array}\right|+\left|\begin{array}{cc}
Y_{3} & X_{3} \\
Y_{1} & X_{1}
\end{array}\right|\right\}
$$

The unit normal vector of the TIN $\vec{n}=\left(n_{1}, n_{2}, n_{3}\right)$ is the cross-product of $\vec{a}=\left(a_{1}, a_{2}, a_{3}\right)$ and $\vec{b}=\left(b_{1}, b_{2}, b_{3}\right)$.

$$
\mathbf{n}=\vec{a} \times \vec{b}=\left[\left|\begin{array}{ll}
a_{2} & a_{3} \\
b_{2} & b_{3}
\end{array}\right|,-\left|\begin{array}{cc}
a_{1} & a_{3} \\
b_{1} & b_{3}
\end{array}\right|,\left|\begin{array}{cc}
a_{1} & a_{2} \\
b_{1} & b_{2}
\end{array}\right|\right]
$$

$$
\text { Where } \begin{aligned}
& a_{1}=X_{3}-X_{1} \\
& a_{2}=Y_{3}-Y_{1} \\
& a_{3}=Z_{3}-Z_{1} \\
& b_{1}=X_{2}-X_{1} \\
& b_{2}=Y_{2}-Y_{1}
\end{aligned}
$$

$$
b_{3}=Z_{2}-Z_{1}
$$

We can also define the a general direction angle $\beta$ as the included angle of the $\vec{n}$ and $\vec{X}$. For a certain angle between $\overrightarrow{n_{a}}$ and $\overrightarrow{n_{b}}$, it can be regarded as $\alpha$.This can be described as below:

$$
\cos \beta=\frac{\vec{n} \bullet \vec{x}}{|\vec{n}||\vec{x}|}=\frac{n_{1}}{\sqrt{n_{1}^{2}+n_{2}^{2}+n_{3}^{2}}}
$$

$\cos \alpha=\frac{\overrightarrow{n_{a}} \bullet \overrightarrow{n_{b}}}{\left|\overrightarrow{n_{a}}\right|\left|\overrightarrow{n_{b}}\right|}=\frac{n_{1} n_{4}+n_{2} n_{5}+n_{3} n_{6}}{\sqrt{n_{1}^{2}+n_{2}^{2}+n_{3}^{2}} \sqrt{n_{4}^{2}+n_{5}^{2}+n_{6}^{2}}}$

\begin{tabular}{|c|c|c|}
\hline Graphical & \multicolumn{2}{|c|}{ Literal Explanation } \\
\hline & $\bar{\beta}=\frac{\sum_{i=1} \beta_{i}}{n}$ & $\begin{array}{l}\text { Mean value of } \\
\text { the normal } \\
\text { vector direction } \\
\text { angle } \beta \text { in one } \\
\text { grid }\end{array}$ \\
\hline & $S_{\beta}=\sqrt{\frac{\sum_{i=1}^{n}\left(\beta_{i}-\bar{\beta}\right)^{2}}{n}}$ & $\begin{array}{c}\text { Standard } \\
\text { deviation of the } \\
\text { normal vector } \\
\text { direction } \\
\text { angle } \beta \text { in one } \\
\text { grid }\end{array}$ \\
\hline 19 & $\bar{h}=\frac{\sum_{i=1}^{n} h_{i}}{n}$ & $\begin{array}{l}\text { Mean value of } \\
\text { the normal } \\
\text { vector direction } \\
\text { angle } h \text { in one } \\
\text { grid } \\
\end{array}$ \\
\hline \begin{tabular}{l|l}
$h_{1}$ & $h_{2}$ \\
\end{tabular} & $S_{h}=\sqrt{\frac{\sum_{i=1}^{n}\left(h_{i}-\bar{h}\right)^{2}}{n}}$ & $\begin{array}{l}\text { Standard } \\
\text { deviation of the } \\
\text { normal vector } \\
\text { direction } \\
\text { angle } h \text { in one } \\
\text { grid } \\
\end{array}$ \\
\hline
\end{tabular}

where $\left(n_{1}, n_{2}, n_{3}\right)=$ unit normal vector of $\overrightarrow{n_{a}}$

$$
\left(n_{4}, n_{5}, n_{6}\right)=\text { unit normal vector of } \overrightarrow{n_{b}}
$$

\subsubsection{Obtain the Sandy Beach}

After the data is Grided, the features of the sandy beach is transformed into the mathematical language: Choose grids which include points at the extracted water surface profile as seed.

Calculate the mean value and standard deviation of the normal vector direction angle $\beta$ and elevation $h$ of each grids.

Table 1: Description of features based on grids

Therefore, the whole set which contains every grids' four feature values can be described as T. 


$$
T=\left(\begin{array}{ccc}
t_{11} & \ldots & t_{14} \\
\vdots & \ddots & \vdots \\
t_{n 1} & \cdots & t_{n 4}
\end{array}\right)
$$

where $\quad t_{i 1}=$ mean value of elevation of the $i^{\text {th }}$ grid.

$t_{i 2}=$ std. of elevation of the $i^{\text {th }}$ grid. $(i=1,2 \ldots, n)$

$t_{i 3}=$ mean value of unit normal vector direction angle of the $i^{t h}$ grid. $(i=1,2 \ldots, n)$

$t_{i 4}=$ std. of unit normal vector direction angle of the $i^{\text {th }}$ grid. $(i=1,2 \ldots, n)$

Then we should determine the threshold for the 8Neighbourhood filling process. Select grids at water surface profile on the sandy beach. Count the frequency of value in $t_{i 1}, t_{i 2}, t_{i 3}, t_{i 4}(i=1,2, \cdots, n)$, and set the mode $\left(s_{1}, s_{2}, s_{3}, s_{4}\right)$ as reference value. If the grid is the sandy area, the mean value and variance of the normal vector directions should be in the range as $\left(s_{1}, s_{1}+\xi_{1}\right)$, $\left(s_{2}-\xi_{2}, s_{2}+\xi_{2}\right),\left(s_{3}-\xi_{3}, s_{3}+\xi_{3}\right),\left(s_{4}-\xi_{4}, s_{4}+\xi_{4}\right)$.

Begin with the water surface profile grids, apply eightneighborhood filling method (Figure 6), if the feature is similar to the sandy beach (within the range mentioned above), new points will be added.

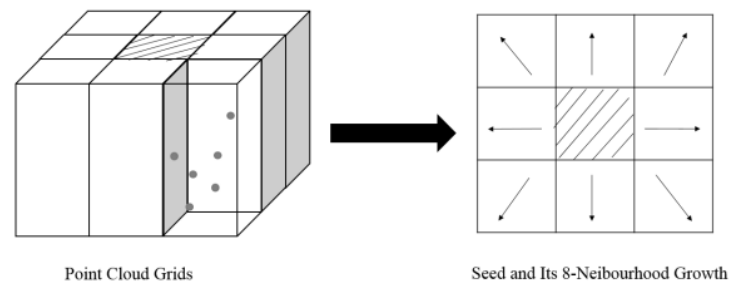

Figure 6: Explanation of 8-Neighbourhood growth method based on grids.

\subsection{Gain the Sandy Beach Shoreline}

The intensity information is related to the humidity of the beach. It is known that water has a relatively low reflectivity in almost all bands (generally lower than 10\%). As Green and IR frequencies are available in a single system, we can observe the humidity degree through intensity image. From the intensity image of sandy beach area, we could extract the boundary between the wet area and dry area, which can be considered as shoreline.

The wet/dry area boundary is related to the wave crests which appears when $c$ is a certain value. When exceeding the value, the area should be the dry beach, otherwise it should be wet. To determine the threshold and extract dry area on the sandy beach, we compared the intensity image with its intensity histogram (Figure 7). It could be concluded from the intensity image: (1) The difference of intensity value of the wet and the dry area is easy to tell apart. The wet area is dark (low value) and the dry area (high value generally higher than 650) is white. (2) The wet and dry area has a certain proportion which can be estimate from the image. Therefore we can narrow the threshold range by conclusion proposed above. With some experiment, we can determine the final threshold $c$.

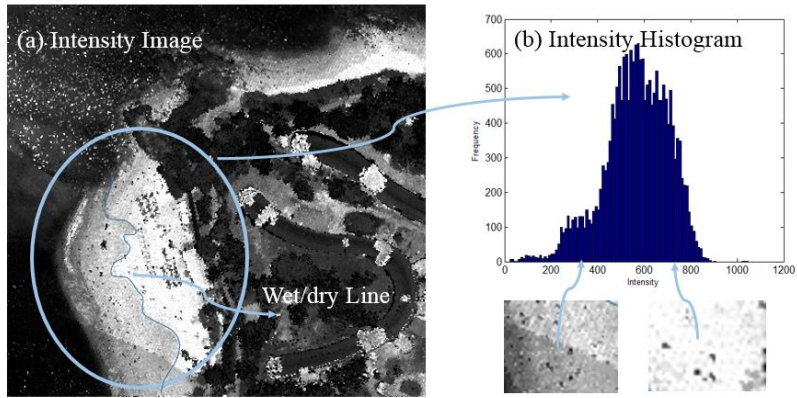

Figure 7: Comparison between intensity image and intensity histogram: (a) Intensity image of part of the sandy beach. (b) Intensity histogram of sandy beach showed in (a).

\subsection{Gain the island shoreline}

The elevation of the shoreline point should be approximately same as the island doesn't covers a big area. In this paper we utilize least square method to fit a plane with the sandy beach shoreline data, and use this plane intersecting the ground point cloud gained by TIN progressive filtering method. After obtaining the plane, we intersect the two surface using method in 2.3 and therefore gain the whole shoreline of this island.

\section{EXPERIMENT}

\subsection{Gain Water Surface Profile}

To gain the water surface profile, we needed both water surface and ground surface. For water surface, it was well fitted with RMSE reaching 0.1 . For ground surface, the ground points were obtained by the TIN progressive filtering method. To obtain this results, we set corresponding parameter as below:

\begin{tabular}{|c|c|c|c|}
\hline $\begin{array}{c}\text { Building } \\
\text { Width(m) }\end{array}$ & $\begin{array}{c}\text { Iterative } \\
\text { Distance(m } \\
)\end{array}$ & $\begin{array}{c}\text { Terrain } \\
\text { Angle }^{\circ} \text { ) }\end{array}$ & $\begin{array}{c}\text { Iterative } \\
\text { Angle }\end{array}$ \\
\hline 5 & 1.5 & 80 & 10 \\
\hline
\end{tabular}

Table 2: Maximum threshold for method

The results (Figure 8) showed the TIN well retained the feature of beaches of three types with RMSE reaching 0.09. Meanwhile, the surface was also referred as a foundation of the extraction of sandy beach (2.4)
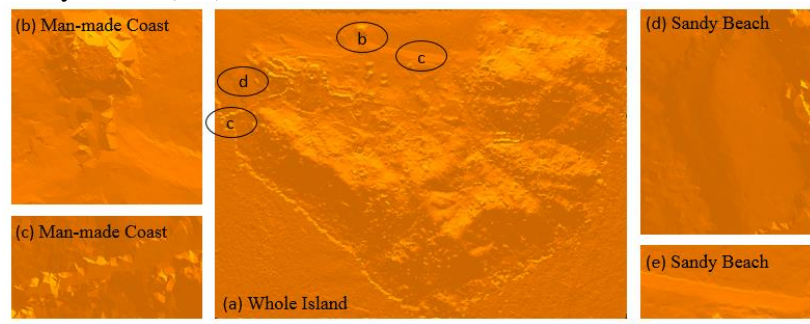

Figure 8: Ground surface of Wuzhizhou Island: (a) whole island ground surface. (b) Enlarged view of a man-made coast

(position b). (c) Enlarged view of a Man-made coast (position c). (d) Enlarged view of sandy beach (position d). (e) Enlarged view of sandy beach (position e).

After obtaining two surface, we got the intersection line as below, the blue line represents water surface profile (Figure 9). For man-made coast, water surface profile obtained based on it 
can be regards as shoreline. For sandy beach and gravel beach, more work was needed.

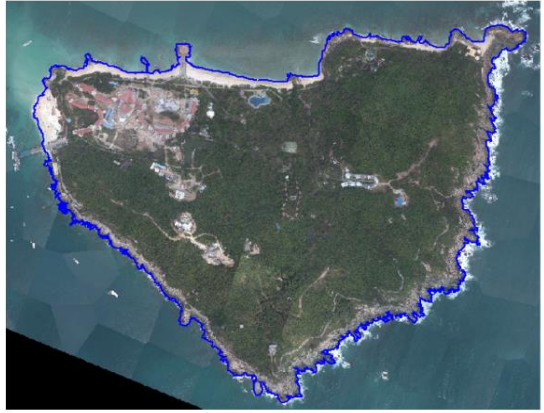

(a) Whole Island

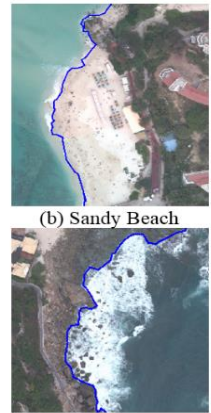

(c) Gravel Beach
Figure 9: Extraction result of water surface profile: (a) the Whole Island water surface profile; (b) Enlarged view of sandy beach water surface profile; (b) Enlarged view of gravel beach water surface profile;

\subsection{Gain the Sandy Beach Shoreline}

To obtain the sandy beach, we should determine the thresholds for 8-neighborhood filling, the normal vector of all triangles in TIN which was obtained from water surface profile point cloud was plotted (Figure 10).

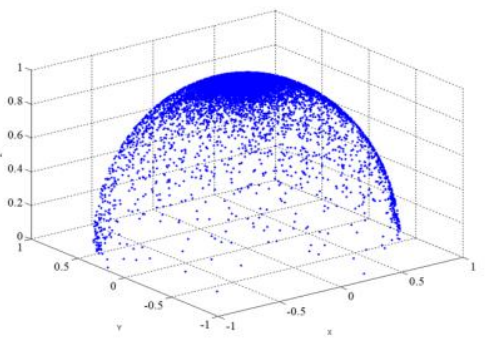

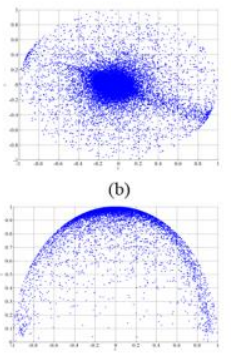

(c)
Figure 10: Normal vector direction of all triangles in TIN: (a)

Normal vector direction in 3D space; (b) Normal vector direction in $\mathrm{X}-\mathrm{Y}$ view. (c) Normal vector direction in $\mathrm{X}-\mathrm{Z}$ view.

It could be observed that triangles' normal vector gathered around a certain range that $n_{1}$ varies in $(-0.3,0.2), n_{2}$ varies in $(-0.2,0.3)$ and $n_{3}$ varies in $(0.9,1)$. By our experiment and observation of Figure 10, we had the threshold setting as below (Table 3):

\begin{tabular}{|c|c|c|c|}
\hline $\begin{array}{c}\text { Elevation } \\
(\mathrm{m})\end{array}$ & $\begin{array}{c}\text { Elevation } \\
\text { Std. }\end{array}$ & $\begin{array}{c}\text { Fault- } \\
\text { Tolerant For } \\
\text { Elevation } \\
\text { mean } \\
\text { value }(\mathrm{m})\end{array}$ & $\begin{array}{c}\text { Fault- } \\
\text { Tolerant For } \\
\text { Elevation } \\
\text { Std. }\end{array}$ \\
\hline-12.35 & 0.26 & 2.05 & 0.14 \\
\hline $\begin{array}{c}\text { Angle } \\
\text { Mean Value } \\
\text { (rad) }\end{array}$ & $\begin{array}{c}\text { Angle } \\
\text { Std. }\end{array}$ & $\begin{array}{c}\text { Fault- } \\
\text { Tolerant For } \\
\text { Angle mean } \\
\text { value(rad) }\end{array}$ & $\begin{array}{c}\text { Fault- } \\
\text { Tolerant For } \\
\text { Angle Std. }\end{array}$ \\
\hline 1.60 & 0.19 & 0.21 & 0.01 \\
\hline
\end{tabular}

Table 3: Parameter setting for 8-neighborhood filling process

Use part of the Island as example. Figure 11 shows the sandy beach extraction result. Figure 11 (a) (c) shows the good extraction accuracy of water/beach line while Figure 11 (b) (d) shows the extraction sifts out some non-beach points.
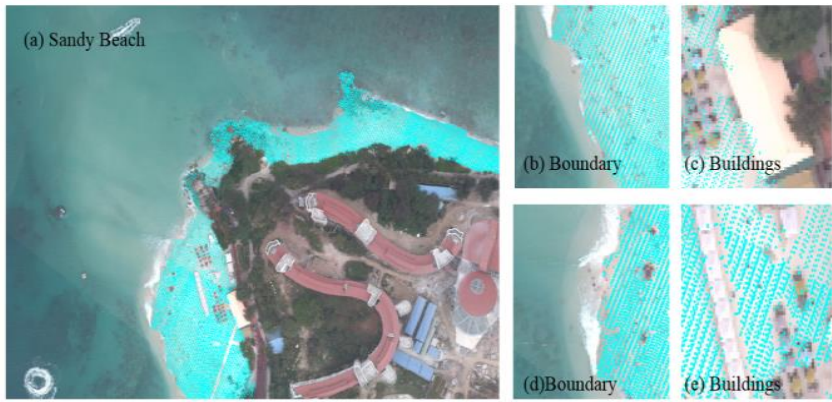

Figure 11: Extraction result of sandy beaches: (a) part of the sandy beaches; (b) (d) Enlarged view which suggested it avoids the influence of buildings; (c) (e) Enlarged view which suggested the extraction result on boundary.

There was several wave crests in the histogram. For better threshold determination, we implemented several experiment, and determined the value as $c=720$. The extraction results is showed as below (Figure 12): the blue points is the dry points and the line is the wet-dry line, regarded as shoreline here.

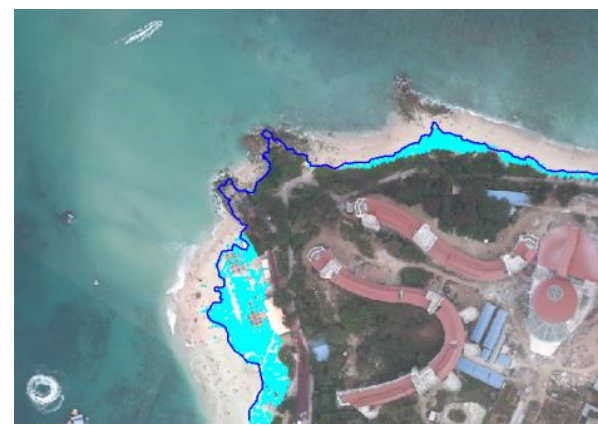

Figure 12 The Extraction Result of wet-dry line

\subsection{Gain the Island Shoreline}

By fitting all sandy beach point cloud to a plane and having it intersected with the ground surface, we had the results as below (Figure 13): the black points under the blue line indicated the points higher than water surface profile but lower than the shoreline, which had a relatively high intensity value.

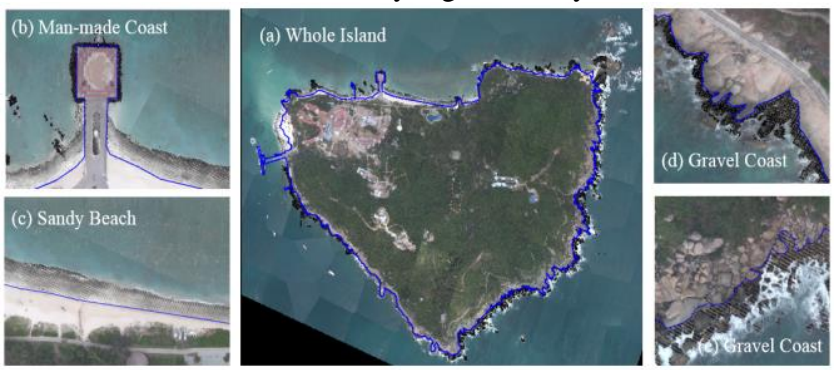

Figure 13: Extraction result of island shoreline: (a) Shoreline of the whole island; (b) Enlarged view which shows the Man-made Coast Shoreline; (c) Enlarged view which shows the sandy beach Shoreline; (d) Enlarged view which shows the gravel coast Shoreline (big rocks); (e)Enlarged view which shows the gravel coast Shoreline (small rocks)

The length of the whole shoreline in this region is about $5.4 \mathrm{~km}$. There are three kinds of regions in the island. The first kind is man-made shore without rocks and sandy. The second kind is sandy beach and the last one is shore consist of rocks. 
To identify the accuracy of shoreline extraction, we used measured data as ground truth for comparison purposes. This paper regarded measured shoreline as reference line, then set an interval for calculating the error distance. To calculate the error distance, we created nodes on the reference line using the interval defined before, then draw normals for every node and the normals would intersect with the extracted shoreline. After calculating the distance between the intersection point and the node on the reference line, we obtained the comparison result as below (Table 4):

Table 4: Accuracy assessment of proposed method.

There's a region which have big error, which locates at the sandy beach where people usually dose a lot of activities and these activities therefore make the wet/dry line not a good

\begin{tabular}{|l|c|c|c|}
\hline Coast Type & Length & RMSE & $\begin{array}{c}\text { Maximum } \\
\text { Error }\end{array}$ \\
\hline Man-made Coast & Meters & Meters & Meters \\
\hline Sandy beach Coast & $2,033.24$ & 0.69 & 14.27 \\
\hline Rocks Coast & $3,008.38$ & 0.48 & 6.64 \\
\hline
\end{tabular}

substitute of shoreline. As showed in Figure 14, the measured shoreline (Light Blue) is generally lower than the derived shoreline (Dark Blue).But this error can be reduced by later fitting method. And the error of rocks coast may resulted from the difference of terrain and location. Even the study area is small, the shoreline elevation will be slightly different, but the error is still within acceptable limits.

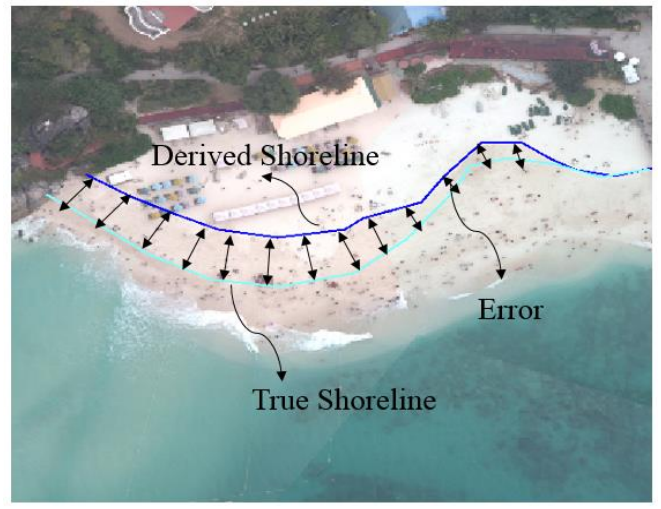

Figure 14 The region which have big error

\section{DISCUSSION}

For the extraction of the shoreline, semantic information was used in our research, which helped to narrow the study area, therefore enhanced the efficiency and accuracy of the proposed method compared to previous researches.

For extracting the water surface profile, traditional applications used single wavelength LiDAR devices. To extract water body precisely, they had to to grid all point cloud and use regional growth method which is a time-consuming way (change Wang $\mathrm{Z}$ Y et al., 2010). As for the dual-laser data could penetrate the water and get the under-water ground points, we didn't need to precisely extract shorelines just depend on water surface point cloud, therefore the accurate boundary of the water surface was not of importance. Obtaining the fitting water surface with the roughly picked water point cloud and having it intersecting with the ground surface helped us determining the water surface profile. Meanwhile, the TIN also provided precise foundation for later process such as water surface profile and sandy beach extraction.
For extracting the sandy beach, the gridding method also effectively simplified the data, improve processing efficiency while it also made it easy to use mature algorithm in photogrammetry and digital image processing. Meanwhile it helped to overcome the error caused by data gap, therefore met processing accuracy requirements.

For extracting the whole island shoreline, the relatively low error also suggested it's feasible to obtain the shoreline by supposing that shoreline in small area have similar elevation.

But it also have limits that it cannot work well when the study area has no sandy beach or the region is too large for us to suppose the shoreline is at a relatively similar elevation.

\section{CONCLUSION}

This paper achieved the extraction of the whole island coastline by semantic information and dual-wavelength LiDAR data. We first obtained the lower boundary of sandy beaches by the utilizing characteristics of dual-wavelength LiDAR data and the features of water. The lower boundary of sandy beaches (water surface profile) provided the elevation basis of sandy beaches. In order to enable the implementation of the regional growth algorithm, the point cloud was gridded. Then with the features and regional growth method we extracted sandy beach. On the sandy beaches, the wet/dry lines of a single beach are extracted using the characteristics of the dual-wavelength LiDAR data and the difference in the intensity information on two sides of the wet /dry lines. After that, as the tidal effects on the coast are almost the same, with the use of extracted beach coastline point cloud we fitted a plane, and use this plane to intersect the ground point cloud to get the entire island coastline. By compared with the Land surveying shoreline, the results showed that the proposed method can successfully extract shoreline with the RMSE varies in 0.32 and 0.69 meters. This method helps to derive precise shoreline by single phase data. Moreover, it offers a new approach to extracting the shoreline when land surveying or tide table are not accessible. Meanwhile, it also has limitation when the region has no sandy beach.

\section{ACKNOWLEDGEMENT}

The authors thank School of Remote Sensing Information and Information Engineering, Wuhan University and Key Laboratory for National Geographic for providing the device and data of Wuzhizhou Island. This research is partial funded by National Natural Science Foundation of China (No. 41101417)

\section{REFERENCES}

E. H. Boak and I. L. Turner, "Shoreline definition and detection: A review," Journal of Coastal Research, vol. 21, no. 4, pp. 688-703, 2005.

D. Bellomo, M. J. Pajak, and J. Sparks, "Coastal flood hazards and the national flood insurance program," Journal of Coastal Research, vol. 28, pp. 21-26, 1999.

Harris M., J. Brock, A. Nayegandhi, and M. Duffy. 2005. Extracting Shorelines from NASA Airborne Topographic LidarDerived Digital Elevation Models. Open-File Report 2005-1427. U.S. Geological Survey. Accessed April 4, 2008, at http://pubs.usgs.gov/of/2005/1427/ofr-2005-1427.pdf. 
Leatherman, S.P., 1983. Shoreline mapping: a comparison of techniques. Shore and Beach 51 (3), 28-33.

Douglas, B.C., Crowell, M., Leatherman, S.P., 1998. Considerations for shoreline position prediction. Journal of Coastal Research 14 (3), 1025-1033.

Leatherman, S.P., Dean, R.G., 1991. Coastal erosion zone management. EOS Transaction 72, 9-10.

Douglas, B.C., Crowell, M., 2000. Long-term shoreline position prediction and error propagation. Journal of Coastal Research $16(1), 145-152$.

Jackson, C.W., Alexander, C., Bush, D.M., 2007. Back-barrier shoreline change history: Cumberland Island, Georgia, 1857e2002. Southeastern Geology 45(2), 73-85.

Jackson, C.W., Bush, D.M., Neal, W.J., 2009. The coastal compartment management plan: using Puerto Rico as a model. Southeastern Geology 46 (2), 69-84.

Yang, B.Y., Madden, M., Kim, J.W., Jordan, T., 2012a. Geospatial analysis of barrier island beach availability to tourists. Tourism Management 33, 840-854.

Leatherman, S.P., 2003. Shoreline change mapping and management along the U.S.East Coast. In: Byrnes, M., Crowell, M., Fowler, C. (Eds.), Shoreline Mapping and Change Analysis: Technical Considerations and Management Implications. Journal of Coastal Research, Special Issue, vol. 38, pp. 5-13.

Pe'eri, S., Long, B., 2011. LiDAR technology applied in coastal studies and management. In: Pe'eri, S., Long, B. (Eds.), Applied LiDAR Techniques. Journal of Coastal Research, Special Issue, vol. 62, pp. 1-5.

Raber, G.T., Jensen, J.R., Hodgson, M.E., Tullis, J.A., Davis, B.A., Berglund, J., 2007. Impact of LiDAR nominal postspacing on DEM accuracy and flood zone delineation. Photogrammetric Engineering and Remote Sensing 73 (7), 793804.

Robertson, W., Whitman, D., Zhang, K., Leatherman, S.P., 2004. Mapping shoreline position using airborne laser altimetry. Journal of Coastal Research 20 (3), 884-892.

Sallenger, A.H., Krabill, W.B., Swift, R.N., Brock, J., List, J., Hansen, M., Holman, R.A., Manizade, S., Sontag, J., Meredith, A., Morgan, K., Yunkel, J.K., Frederick, E.B., Stockdon, H.F., 2003. Evaluation of airborne topographic LiDAR for quantifying beach changes. Journal of Coastal Research 19 (1), 25-133.

Stockdon, H.F., Sallenger, A.H., List, J.H., Holman, R.A., 2002. Estimation of shoreline position and change using airborne topographic LiDAR data. Journal of Coastal Research 18 (3), $502-513$

Brzank A, Heipke C, Goepfert J, Soergel U. 2008. Aspects of generating precise digital terrain models in the Wadden Sea from lidar-water classification and structure line extraction. ISPRS Journal of Photogrammetry and Remote Sensing, 63(5): 510-528 [DOI: 10.1016/j.isprsjprs.2008.02.002]

Wang Z Y, Ma H C, Xu H G and Peng J G. 2010. A method for extracting water contour lines from LiDAR point clouds data.
Geomatics and Information Science of Wuhan University, 35(4): $432-435$

Sithole, G., Vosselman, G. (2003) Comparison of Filtering Algorithms International Archives of Photogrammetry, Remote Sensing and Spatial Information Sciences, vol. 34, part 3/W13, Dresden, Germany, pp. 71-78.

Axelsson. DEM generation from laser scanner data using adaptive TIN models.International Archives of Photogrammetry and Remote Sensing,2000, 33(B4):110 -117

Gong L, Zhang Y S, Li Z G and Bao Q F. 2012. A filtering method of airborne LiDAR data based on hierarchical pseudogrid concept and slope threshold. Science of Surveying and Mapping, 37(1): 101-103 